\title{
Angiographic Assessment of Exercise Treadmill Test-Detected Occult Coronary Artery Disease in Type 2 Diabetics
}

\author{
Nabeel N.F. Hadeed ${ }^{1} C A B M, F R C P$ (London), Dhiyaa A. Ahmad ${ }^{1}$ FICMS, Faris M. Lolan ${ }^{1}$, FICMS, \\ Talal A.M. Al-Hadeedi' ${ }^{2}, C A B M$, Abdulrahman N.H. Al-Dabbagh ${ }^{2}, C A B M$, \\ Sufian D. Al-Hayali ${ }^{3}$, FICMS, Mahmood S.N. Al-Hadedy ${ }^{2}, C A B M$ \\ ${ }^{1}$ Nineveh College of Medicine, Mosul, Nineveh, Iraq, ${ }^{2}$ As-Salam Teaching Hospital, Mosul, Nineveh, Iraq, ${ }^{3} \mathrm{Ibn}-$ Seena \\ Teaching Hospital, Mosul, Nineveh, Iraq
}

\begin{abstract}
Background Myocardial ischemia in type 2 diabetes mellitus may be painless keeping the coronary artery disease occult. Exercise Treadmill Test was one of the modes that have been tried to uncover occult coronary artery disease, yet its results were not assessed.

Objective To show the rate of occult coronary artery disease in asymptomatic type 2 diabetes mellitus subjects using exercise treadmill test, and to assess the exercise treadmill test-detected occult coronary artery disease by conventional coronary angiography, and to inspect the risk factors.

Methods A cross sectional study of 120 randomly enrolled asymptomatic type 2 diabetic subjects who were not labeled to have ischemic heart disease prior to the study. The body mass index, blood pressure, serum total cholesterol, serum triglycerides and glycated hemoglobin A1c were all measured in addition to rating of smoking trend. Exercise treadmill test was, then, conducted to all of the enrolled subjects followed by conventional coronary angiography to subjects whose exercise treadmill test was positive.

Results A proportion of $20.8 \%$ of asymptomatic type 2 diabetic subjects showed positive exercise treadmill test results $(\mathrm{p}<0.05)$. On assessing the exercise treadmill test positive subjects by conventional coronary angiography, $68.4 \%$ proved to have true coronary artery stenosis; $69 \%$ of them were significant stenosis affecting 1-3 coronary vessels. Smoking trend was the most significant risk factor in type 2 diabetics who proved to have positive exercise treadmill test results, particularly among the males.

Conclusions One fifth of asymptomatic type 2 diabetic subjects have occult coronary artery disease when screened by exercise treadmill test. Two thirds of the exercise treadmill test-diagnosed occult coronary artery disease subjects have significant coronary stenosis when assessed by conventional coronary angiography. Smoker type 2 diabetic subjects, in particular males, are at risk and should be keenly screened for occult coronary artery disease.

Key words Type 2 diabetes, Ischemic, Silent, Occult, Coronary angiography, Exercise treadmill, Smoking.
\end{abstract}

List of abbreviation: $T 2 D=$ Type 2 diabetes mellitus, $C A D=$ Coronary artery disease, $\mathrm{OCAD}=$ Occult coronary artery disease, $\mathrm{ETT}=$ Exercise treadmill test, DIAD = Detection of silent myocardial ischemia in asymptomatic diabetic, $\mathrm{CAG}=$ coronary angiography, $\mathrm{ECG}=$ Electrocardiography, $\mathrm{BMI}=$ Body mass index, $\mathrm{HbA1c}=$ Glycated hemoglobin A1c

\section{Introduction}

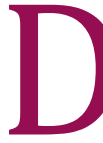
iabetes mellitus is a strong independent risk factor for the development of atherosclerosis ${ }^{(1)}$ and predisposes to the development of other known risk factors, such as hyperlipidemia ${ }^{(2)}$ and hypertension ${ }^{(3)}$. 
Based on the Framingham's cohort study, Kannel and McGee, long ago, had demonstrated that diabetic individuals had a two-to-three folds increased risk of developing atherosclerosis including coronary heart disease ${ }^{(4)}$. In the report of the Adult Treatment Panel of the National Cholesterol Education Program ${ }^{(5)}$, type 2 diabetes mellitus (T2D) was accorded a coronary artery disease (CAD) riskequivalent ${ }^{(6)}$. The extraordinary frequency with which CAD occurs in diabetes lead researchers to inversely describe T2D as "a cardiovascular disease associated with hyperglycemia" (7).

Myocardial ischemia due to CAD, may presents acutely or chronically with variable degrees of myocardial damage and dysfunction. Concerning symptoms, myocardial ischemia is usually associated with pain but it may be painless or silent. Non-perception of myocardial ischemia keeps CAD dormant. The term occult CAD (OCAD) has been, commonly, used to describe silent (painless) myocardial ischemia and vice versa .

According to its severity, OCAD may be recovered coincidentally in a resting electrocardiography (ECG) in the form of ST-T changes, old myocardial infarct changes or left bundle branch block, or detected intentionally by ambulatory ECG (Holter) monitoring during daily activity ${ }^{(8)}$. Otherwise, provocative tests that stress the heart e.g. exercise treadmill test (ETT) or pharmacologic stress tests can be used to uncover it ${ }^{(8,9)}$.

Recently, there is accumulating evidence that patients with diabetes have a high incidence of silent myocardial infarction and ischemia $(9,10,11)$. During ambulatory ECG monitoring, diabetic patients were shown to have a high incidence of transient silent ST segment changes ${ }^{(12)}$. The study entitled "detection of silent myocardial ischemia in asymptomatic diabetic" (DIAD) had shown that silent myocardial ischemia occurs in more than one per five asymptomatic patients with T2D ${ }^{(13)}$.

Since realizing the high rate of silent myocardial ischemia in diabetes, many measures have been tried to uncover the underlying OCAD but controversies exist regarding the optimal screening measure. ETT was one of the modes that had been tried for screening before the emergence of stress echocardiography or nuclear measures. Only, few studies have used conventional coronary angiography (CAG) to examine ETT results in detecting OCAD in diabetic patients.

In this study, we aimed to show the rate of OCAD in asymptomatic T2D patients by using ETT, to assess the positive ETT results by conventional CAG, and to inspect the risk factors among the afflicted subjects.

\section{Methods}

This is a cross sectional study that was conducted at As-Salam Teaching Hospital and Ibn-Seena Teaching Hospital in Mosul from January 1, 2011 through January 1, 2013. The subjects were 120 randomly recruited T2D subjects who were not labeled to have ischemic heart disease at any time prior to the study. The subjects' free agreement and consents on the study were taken after discussing the tests and the safety precautions. Exclusion from the study included those who were arthritic and unable to sustain ETT, those who showed abnormal base-line ECG like ST/T changes or bundle branch block, those whose general systemic status was frankly poor, those who aged more than 70 years and those who alleged having claudication on walking. Exclusion from having conventional CAG included those who were atopic or suspected to be allergic to angiography dye.

The contributory data, including age, gender and duration of diabetes, co-morbidities, and drug history were recorded and tabulated. Clinical examination including measurement of body weight, height and estimation of body mass index (BMI) was conducted. Systolic and diastolic blood pressure (Korotkof phases I and $\checkmark$ respectively) were measured as the mean of three measurements with a mercury sphygmomanometer.

Biochemical tests for serum lipid profile were measured to all, and glycated haemoglobin A1C 
(HbA1c) was determined by spectrophotometer (Cecil CE 1011, Cecil Instrument, Cambridge, UK).

After having a 12-lead resting ECG, ETT was conducted to all of the enrolled patients if, otherwise, not contraindicated or refused by the patient. A maximal symptom-limited exercise was used with a treadmill Xscribe $5^{\circledR}$ TM (Mortara instrument, USA) according to Bruce protocol test format. Twelve ECG leads were recorded continuously and blood pressure was measured throughout the test at rest and at the end of each step .

The ETT was defined as maximal if the patient reached $85 \%$ of the predicted heart rate for the age; and the test was regarded as positive if the patient perceived chest pain and/or a horizontal or down-sloping ST segment depression of $>1 \mathrm{~mm}$. The test was regarded non-conclusive if it was prematurely ended due to fatigue, arrhythmias, cardiac conducting abnormalities, hypotension, or hypertensive reaction (diastolic blood pressure rise to 115 $\mathrm{mmHg}$ and/or systolic blood pressure to 250 $\mathrm{mmHg}$ ) before the occurrence of any pain or ST-T changes (14). Cardiovascular drugs including beta-blockers and calcium-channel blockers were stopped 72 hours before the test .

The subjects who showed a positive ETT results were then shifted to have CAG at the cardiology lab of Ibn-Seen Teaching Hospital within 30 days of their ETT. Conventional CAG was performed and evaluated by two independent expert observers. According to Coronary Artery Surgery Study criteria, angiograms were graded as significant if the luminal diameter narrowing of the left main coronary artery was $\geq 50 \%$ or the left anterior descending, left circumflex, right coronary arteries or their major branches was $\geq 70 \%{ }^{(15)}$.

The data were expressed as mean \pm SD. An X2 test was used to study the distribution of proportional data (gender and smoking) among positive and negative ETT subjects. Independent two sample structure T-test was used to compare the difference in mean of continuous variables; age, duration, total cholesterol (T. Chol), triglycerides (TG), BMI, systolic and diastolic blood pressures (BP) and $\mathrm{HbA} 1 \mathrm{c} \%$ between the positive and negative ETT. All the data were processed using statistical package SPSS version (Chicago Inc. ILL). A p-value $<0.05$ was considered statistically significant.

\section{Results}

Out of the 120 asymptomatic diabetics that have been enrolled in this study, the males ( $\mathrm{n}$ 66) constituted $54 \%$ of the sample and the females ( $n$ 54) constituted $46 \%$. The subjects' mean age $\pm S D$ was $49.41 \pm 8.9$ years, duration of diabetes was $7.5 \pm 6$ years and $\mathrm{HbA} 1 \mathrm{c} \%$ was $8.24 \% \pm 1.5 \%$.

On submitting the subjects (n 120) to ETT, onefifth (n 25) (=20.8\% of the sample) showed positive results $(p<0.05)$, about two thirds (70.83\%) showed a negative results and nearly one-tenth $(8.33 \%)$ were non-conclusive. When the subjects with non-conclusive ETT (n 10) were dropped, the rate of subjects with positive ETT then rose to $22.72 \%$ (Table 1 ). The proportion of positive ETT results among the males was $15 / 66(22.7 \%)$ and among the females was 10/54 (18.51\%). The difference between the two proportions was nonsignificant (NS). However, the rate of nonconclusive ETT results among the males was significantly lower than among the females (3\% vs. $14.8 \%$ ) respectively $(p<0.05)$ (Table 1$)$.

When the subjects with positive ETT (n 25) were shifted to have conventional CAG, 6 of them ( 3 males and 3 females) didn't agree to do the angiography. The remaining 19 subjects who accepted sustaining angiography showed that two thirds of them $(13 / 19=68.4 \%)$ have coronary artery stenosis and one third (6/19= $31.5 \%)$ have apparently normal coronaries. The stenoses were of variable degrees as follows; $69.24 \%$ (9/13) was significant stenosis of $1-3$ coronary vessels and $30.76 \%$ (4/13) was nonsignificant stenosis (Table 2). The rate of angiographic stenosis among males was $9 / 12$ $(=75 \%)$ and among females was $4 / 7 \quad(=57 \%)$ 
with NS difference (Table 2). The rate of coronary stenosis on angiography in regard to the total sample of asymptomatic diabetics was $10.8 \%$.

Regarding the risk factors, smoking trend was outstandingly different between positive and negative ETT subjects $(32 \%$ vs. $16 \%$ respectively) and between positive ETT males and females ( $53 \%$ vs. $0 \%$ respectively) ( $p<0.05$ in both) (Table 1). Other cardiovascular risk factors, including age, duration of diabetes, systolic and diastolic blood pressure, BMI and $\mathrm{HbA1c}$, were shown to be higher among the females, particularly the ETT positive although statistically insignificant (Table 1). In the subgroup that sustained CAG, there were no significant differences in risk factors between the positive and the negative CAG subjects .

Table 1. Positive, negative and non-conclusive ETT among asymptomatic T2D subjects and the risk factors of OCAD including age, duration of diabetes, T. Chol, TG, BMI, blood pressure, HbA1c and smoking

\begin{tabular}{|c|c|c|c|c|c|c|c|c|c|}
\hline \multirow[b]{2}{*}{ Parameters } & \multicolumn{3}{|c|}{$\begin{array}{l}\text { Positive ETT } \\
(20.8 \%)\end{array}$} & \multicolumn{3}{|c|}{$\begin{array}{c}\text { Negative ETT } \\
(\mathbf{7 0 . 8 3 \% )}\end{array}$} & \multicolumn{3}{|c|}{$\begin{array}{l}\text { Non-conclusive } \\
(8.33 \%)\end{array}$} \\
\hline & $\begin{array}{l}\text { Total } \\
\mathrm{N}=25\end{array}$ & $\begin{array}{l}\text { Males } \\
\mathrm{n}=15\end{array}$ & $\begin{array}{c}\text { Females } \\
n=10\end{array}$ & $\begin{array}{l}\text { Total } \\
\mathrm{n}=85\end{array}$ & $\begin{array}{c}\text { Males } \\
n=49\end{array}$ & $\begin{array}{c}\text { Females } \\
n=36\end{array}$ & $\begin{array}{l}\text { Total } \\
\mathrm{n}=10\end{array}$ & $\begin{array}{c}\text { Males } \\
\mathrm{n}=2\end{array}$ & $\begin{array}{c}\text { Females } \\
n=8\end{array}$ \\
\hline Age & $\begin{array}{r}50.2 \\
\pm 7.85 \\
\end{array}$ & $\begin{array}{c}47.4 \\
\pm 7.30\end{array}$ & $\begin{array}{c}53 \\
\pm 7.76 \\
\end{array}$ & $\begin{array}{l}49.21 \\
\pm 7.68\end{array}$ & $\begin{array}{l}50.42 \\
\pm 7.84\end{array}$ & $\begin{array}{c}48 \\
\pm 7.49 \\
\end{array}$ & \multicolumn{3}{|c|}{ p NS } \\
\hline Duration & $\begin{array}{r}7.63 \\
\pm 6.09 \\
\end{array}$ & $\begin{aligned} & 6.37 \\
& \pm 4.48 \\
&\end{aligned}$ & $\begin{array}{l}9.02 \\
\pm 7.9\end{array}$ & $\begin{array}{c}7.62 \\
\pm 6.43\end{array}$ & $\begin{array}{r}7.25 \\
\pm 5.43 \\
\end{array}$ & $\begin{array}{r}8.13 \\
\pm 7.64 \\
\end{array}$ & \multicolumn{3}{|c|}{ p NS } \\
\hline T. Chol & $\begin{array}{c}5.42 \\
\pm 1.33\end{array}$ & $\begin{array}{c}5.62 \\
\pm 1.57\end{array}$ & $\begin{array}{c}5.22 \\
\pm 0.72\end{array}$ & $\begin{array}{c}5.32 \\
\pm 1.09\end{array}$ & $\begin{array}{r}5.20 \\
\pm 0.87\end{array}$ & $\begin{array}{r}5.45 \\
\pm 1.33\end{array}$ & \multicolumn{3}{|c|}{ p NS } \\
\hline TG & $\begin{array}{c}1.65 \\
\pm 0.75 \\
\end{array}$ & $\begin{array}{c}1.72 \\
\pm 0.18 \\
\end{array}$ & $\begin{array}{r}1.59 \\
\pm 0.67 \\
\end{array}$ & $\begin{array}{c}1.79 \\
\pm 0.87\end{array}$ & $\begin{array}{c}1.85 \\
\pm 0.95 \\
\end{array}$ & $\begin{array}{r}1.72 \\
\pm 0.75 \\
\end{array}$ & \multicolumn{3}{|c|}{ p NS } \\
\hline BMI & $\begin{array}{l}27.55 \\
\pm 1.53 \\
\end{array}$ & $\begin{array}{c}26.5 \\
\pm 3.68 \\
\end{array}$ & $\begin{array}{c}28.6 \\
\pm 7.56 \\
\end{array}$ & $\begin{array}{l}27.96 \\
\pm 1.42 \\
\end{array}$ & $\begin{array}{l}26.37 \\
\pm 3.17 \\
\end{array}$ & $\begin{array}{l}29.56 \\
\pm 2.47\end{array}$ & \multicolumn{3}{|c|}{ p NS } \\
\hline Systolic BP & $\begin{array}{l}148.2 \\
\pm 19.6 \\
\end{array}$ & $\begin{array}{l}142.6 \\
\pm 19.4 \\
\end{array}$ & $\begin{array}{c}154 \\
\pm 18.97\end{array}$ & $\begin{array}{c}141.92 \\
\pm 18.7 \\
\end{array}$ & $\begin{array}{c}136.63 \\
\pm 15.8 \\
\end{array}$ & $\begin{array}{l}147.22 \\
\pm 20.8\end{array}$ & \multicolumn{3}{|c|}{ p NS } \\
\hline Diastolic BP & $\begin{array}{r}89 \\
\pm 9.97 \\
\end{array}$ & $\begin{array}{c}86 \\
\pm 9.1 \\
\end{array}$ & $\begin{array}{c}92 \\
\pm 10.59 \\
\end{array}$ & $\begin{array}{c}85 \\
\pm 9.4 \\
\end{array}$ & $\begin{array}{c}83.36 \\
\pm 8.5 \\
\end{array}$ & $\begin{array}{r}86.66 \\
\pm 10.35 \\
\end{array}$ & \multicolumn{3}{|c|}{ p NS } \\
\hline HbA1c & $\begin{array}{c}8.9 \\
\pm 1.6 \\
\end{array}$ & $\begin{array}{c}8.49 \\
\pm 1.56 \\
\end{array}$ & $\begin{array}{c}9.5 \\
\pm 1.7 \\
\end{array}$ & $\begin{array}{c}9 \\
\pm 2.1 \\
\end{array}$ & $\begin{array}{l}8.8 \\
\pm 2 \\
\end{array}$ & $\begin{array}{c}9.3 \\
\pm 2.23 \\
\end{array}$ & \multicolumn{3}{|c|}{ p NS } \\
\hline $\begin{array}{c}\text { Smoking } \\
\mathrm{N}(\%)\end{array}$ & $\begin{array}{c}8 \\
(32 \%)^{*}\end{array}$ & $\begin{array}{c}8 \\
(53 \%)\end{array}$ & $\begin{array}{c}0 \\
(0 \%)\end{array}$ & $\begin{array}{c}16 \\
(18 \%)^{*}\end{array}$ & $\begin{array}{c}13 \\
(26 \%)\end{array}$ & $\begin{array}{c}3 \\
(8 \%)\end{array}$ & \multicolumn{3}{|c|}{$* p<0.05$} \\
\hline
\end{tabular}


Iraqi JMS 2016; Vol. 14(3)

Table 2. : Positive and normal CAG results after exposing positive ETT subjects to conventional CAG

\begin{tabular}{ccccc}
\hline & $\begin{array}{c}\text { CAG results } \\
\mathrm{n}=19(100 \%)\end{array}$ & $\begin{array}{c}\text { Males } \\
\mathrm{n}=12\end{array}$ & $\begin{array}{c}\text { Females } \\
\mathrm{n}=\mathbf{7}\end{array}$ & $\mathrm{p}$ value \\
\hline $\begin{array}{c}\text { Positive } \\
\mathrm{n}=13(68.4 \%)\end{array}$ & $\begin{array}{c}\text { Non-significant stenosis } \\
\mathrm{n}=4(30.76 \%) \\
\text { Significant stenosis } \\
\mathrm{n}=9(69.24 \%)\end{array}$ & 2 & 2 & NS \\
\hline & $\begin{array}{c}\text { Normal } \\
\mathrm{n}=6(31.6 \%)\end{array}$ & 3 & 3 & NS \\
\hline
\end{tabular}

\section{Discussion}

The high mean \pm SD of $\mathrm{HbA} 1 \mathrm{C} \%$ of the enrolled subjects in general $(8.24 \% \pm 1.5 \%)$ reflects a bad glycemic control. The burden that hyperglycemia imposes on the arteries is multi-factorial including higher expression of cell-adhesion molecule, monocytes recruitment and migration into the intima ${ }^{(16)}$, LDL oxidation ${ }^{(17)}$, foam cell formation ${ }^{(18)}$ and vascular smooth muscle cell migration (19). These defects perpetuate the atherogenesis of coronary arteries in diabetes, rendering it earlier in occurrence and more extensive in spread ${ }^{(20)}$.

In addition, there is a growing evidence that diabetes impedes coronary blood flow before the obstructive changes of atherosclerosis by altering the vasodilator function in, both, the epicardial and resistance coronary vessels (21). Autonomic neuropathy, a major cause of nonperceiving ischemic cardiac pain in diabetes ${ }^{(22,}$ 23), had been found to affect myocardial perfusion ${ }^{(24,25)}$ and to strongly predict silent myocardial ischemia in diabetes ${ }^{(12)}$.

The prevalence of silent ischemia and OCAD in diabetics using different measures of screening widely ranges from $9 \%$ to $75 \%{ }^{(26-30)}$. The exercise test has remained at the heart of the work-up of the cardiac patient since its first proposal by Goldhammer and Scherf ${ }^{(31)}$. The ETT score is a useful and valid tool that can help clinicians to determine prognosis and decide whether to refer outpatients with suspected CAD for cardiac catheterization ${ }^{(32)}$. Much of the diagnostic power of ETT relies on changes in the ST segment during exercise ${ }^{(33)}$. However, several studies had shown that chest pain as a cause of termination of the exercise test has discriminating diagnostic values ${ }^{(34)}$. In diabetic population, the silence of myocardial ischemia calls for a separate assessment of exercise test characteristics ${ }^{(35)}$.

The accuracy of ETT as a screening test of OCAD was reported to be $79 \%$, with a false-negative rate of $18 \%$. For patients who are unable to perform an ETT and for those with a high chance of being 'false negative', alternative screening tests should be performed ${ }^{(36)}$.

The finding, in this study, that $20.8 \%$ of asymptomatic T2D subjects were having OCAD (shown as positive ETT), was in confirmation with the result of Zorlu et al using ETT too ${ }^{(10)}$. The finding was, also, consistent with what Wackerset al had reported in the first step of DIAD study ${ }^{(13)}$ using stress echocardiography for screening the asymptomatic diabetic patients. In stress echocardiography, the patient undergoes pre- and immediately post-exercise ultrasonographic examination of the heart ${ }^{(37)}$. Comparably, the second step of DIAD, using adenosine technitium-99m-sestamibi single photon emission computed tomography (SPECT) and myocardial perfusion imaging has shown that $60 \%$ of asymptomatic diabetics had two or more American Diabetic Association screening risk factors; $50 \%$ were capable of performing low-level exercise but only $22 \%$ had silent ischemia ${ }^{(13)}$.

Some researchers believe that using stress nuclear testing; Thallium-201 and Technitium$99 \mathrm{~m}$-sestamibi, to perform myocardial perfusion imaging increases the diagnostic accuracy over ETT and allows for a more precise assessment of 
myocardium at risk even in single vessel disease, which can be associated with false negative ETT results ${ }^{(38)}$.

Bosson et al stated that, both, stress nuclear testing and stress echocardiography have expanded the potential of ETT to screen patients with baseline ECG abnormalities that prevent adequate evaluation through conventional ECG analysis ${ }^{(37)}$.

To assess the diagnose reliability of ETT, the positive ETT subjects, in this study, were submitted to conventional CAG, the gold standard for the diagnosis of CAD. The results disclosed that two thirds (68.4\%) of positive ETT (10.8\% of the study total sample) were having angiographic coronary stenosis. The discrepancy between OCAD rates as detected by ETT and those detected by CAG in this study $(20.8 .72 \%$ vs. $10.8 \%)$, had, also, been seen when other modalities of screening for OCAD were compared to CAG ${ }^{(39)}$. Using the non-invasive coronary computed tomoangiography (CCTA), for example, had showed that $64 \%$ of asymptomatic diabetic subjects had OCAD but only $26 \%$ of them had a significant stenosis ${ }^{(28)}$.

In regard to gender, less number of females who sustained CAG $(4 / 7=57 \%)$ showed angiographic coronary stenosis in comparison to $75 \%$ of the males. Although statistically non significant, ( due to sample number), the apparently lower rate of positive angiography among females than among males ( $57 \%$ vs. $75 \%$ ), is not merely a false positive ETT result among females. It, rather, reflects a higher rate of small vessel disease among females that was shown as positive ETT but underestimated by conventional CAG. True angina with a negative CAG due to small vessel disease affliction in females is a well known issue ${ }^{(40)}$. In other words, the apparently higher rate of positive CAG among males means that positive ETT males are more likely to have large (epicardial) coronary disease than females who tend to have small vessel disease. Diabetic males thus deserve a keen coronary imaging.

On comparing the detection rates of significant forms of OCAD by the different measures of screening, it was clear that the rates are nearly comparable, ranging between $18 \%{ }^{(41)}$ and $26 \%$
(31). This indicates that ETT that reported an OCAD rate of $20.8 \%$ among asymptomatic T2D subjects in this study is a reasonable practical tool for detecting the significant forms of OCAD. Milder forms of OCAD that are beyond ETT detection can be encompassed in an optimal conservative therapy of diabetes. In addition, having a higher positive angiographic stenosis among males (although statistically nonsignificant) draws attention towards the genuine requirement of T2D males to a specific care to guard against subtle ischemic myocardial damage. Positive ETT results in females, who were shown to less likely have angiographic stenosis, reflect a higher rate of small vessel disease among females in the study sample.

In spite of the repeatedly documented high OCAD rates among asymptomatic diabetics, some studies have failed to show any difference between diabetic subjects and the general population in regard to the prevalence of silent myocardial ischemia. In the remarkable Danish case-control study, the observed prevalence of silent ischemia on ETT or Holter testing in diabetic patients was $13.5 \%$ and was no different in matched controls ${ }^{(41)}$.

Apart from the rate of smoking, the risk factors of the enrolled sample; age, duration of diabetes, BMI, HbA1c, T Chol, TG, systolic and diastolic blood pressures, were not significantly different between the positive and negative ETT subjects. This finding was largely in conformation with Juan et al results except that the latter had reported a significantly older age and longer duration of diabetes among the positive ETT in addition to smoking (29). Moreover, it was quite congruent with Qais study that showed that the frequency of diabetes and smoking was significantly higher in patients with coronary heart disease in comparison to the control group ${ }^{(42)}$.

Our finding indicates that smoking trend is a strong predictor of significant OCAD among T2D subject. The strongest predictors for abnormal screening tests in DIAD study were abnormal Valsalva, male gender, and diabetes duration but not the traditional cardiac risk factors or inflammatory and prothrombotic markers ${ }^{(13)}$. 
In accord with Al-Mukhtar et al ${ }^{(43)}$, the current study found that the females, particularly the ETT positive females, have a higher rate of cardiovascular risk factors. In spite of that the females have less rate of OCAD. This dictates that females have some protective factors against CAD. Coronary protection, in the premenopausal females, is likely to be due to the effect of estrogen hormone that hinders atherogenicity in more than a way ${ }^{(44,45)}$.

This study concluded that when screened by ETT, one fifth of asymptomatic T2D subjects were shown to be afflicted with OCAD. When the ETT-detected OCAD, were assessed by CAG, two thirds of them were found to have angiographic coronary disease; two third of them were of significant stenosis. Smoking in T2D, especially among males, is highly predictive of the presence of OCAD. The Males were afflicted by OCAD at a lower rate of risk factors than females. Thus, ETT should be highly considered in smoker males with T2D.

\section{Acknowledgements}

Acknowledgements for all cardiology unit staff in As-Salam Teaching Hospital and Ibn-Seena Teaching Hospital.

\section{Author contribution}

All authors were contributed in collection of patients sample and interchanged the basic interview as well as the base line assessment of patients.

\section{Conflict of interest}

There is no conflict of interest to be declared.

\section{Funding}

No special funds required for this study as the investigation performed routinely.

\section{References}

1. Reusch Jane EB, Draznin BB. Atherosclerosis in diabetes and insulin resistance. Diabetes, Obesity and Metabolism. 2007; 9(4): 455-63.

2. Mooradian AD. Dyslipidemia in type 2 diabetes mellitus. Nature Rev Endocrinol. 2009; 5(3): 150-9.
3. Bell DSH. Hypertension, diabetes, insulin resistance, and postprandial hyperglycemia. Drug Develop Res. 2006; 67(7): 595-6.

4. Kannel WB, McGee D. Diabetes and Cardiovascular Disease. The Framingham Study. JAMA. 1979; 241(19):2035-8.

5. Report of the Adult Treatment Panel III (ATP III). the 2001 National Cholesterol Education Program guidelines on the detection, evaluation and treatment of elevated cholesterol in adults. Cardiol Clin. 2003; 21(3): 393-8.

6. Whiteley L, Padmanabhan S, Hole D, et al. Should diabetes be considered a coronary heart disease risk equivalent? Results from 25 years of follow-up in the Renfrew and Paisley survey. Diabetes Care. 2005; 28(7): 1588-93.

7. Yudkin JS. Managing the diabetic patient with acute myocardial infarction. Diabet Med 1998; 15: 276 -81. Cited by: Inzucchi SE. Noninvasive Assessment of the Diabetic Patient for Coronary Artery Disease. Diabetes Care 2001; 24(9): 1519-21.

8. Di Carli MF, Hachamovitch R. Should we screen for occult coronary artery disease among asymptomatic patients with diabetes. J Am Coll Cardiol. 2005; 45: 504.

9. Zorlu M, Helvacı A, Kıskaç $M$, et al. Silent myocardial ischemia and related risk factors in patients with type 2 diabetes mellitus. Cüneyt Ardıç --- Mustafa Oran --Mine AdaşDicle Med J. 2010. 37(2): 140-4.

10. Ahmadabadi MN. Pourbehi MR. Assadi M. High prevalence of silent ischemia in asymptomatic type 2 diabetic patients using myocardial perfusion imaging. Iran J Nucl Med. 2010. 18 (Suppl+1): 133.

11. Chiariello $M$, Indolfi $C$, Cotecchia $M R$, et al. Asymptomatic transient changes during ambulatory ECG monitoring in diabetic patients. Am Heart J. 1985; 110: 529-34.

12. Wackers FJ, Young LH, Inzucchi SE, et al. Detection of silent myocardial ischemia in asymptomatic diabetic subjects: the DIAD study. Diabetes Care. 2004; 27: 1954-61.

13. Froelicher V, Morrow K, Brown M, et al. Prediction of atherosclerotic cardiovascular death in men using a prognostic score. Am J Cardiol. 1994; 73 (2): 133-8.

14. Principal Investigators of CASS and their associates. The National Heart, Lung, and Blood Institute Coronary Artery Surgery Study (CASS). Circulation. 1981; 63 (Suppl): 11-39.

15. Fogelstrand L, Hulthe J, Hultén LM, et al. Monocytic expression of CD14 and CD18, circulating adhesion molecules and inflammatory markers in women with diabetes mellitus and impaired glucose tolerance. Diabetologia. 2004; 47(11): 1948-52.

16. Schwenke DC, D'Agostino RB, Goff DC, et al. Differences in LDL oxidizability by glycemic status: the 
Insulin Resistance Atherosclerosis Study. Diabetes Care. 2003; 26: 1449-55.

17. Cui X, Kushiyama A, Yoneda M, et al. Macrophage foam cell formation is augmented in serum from patients with diabetic angiopathy. Diabetes Res Clin Pract. 2010; 87(1): 57-63.

18. Faries $\mathrm{PL}$, Rohan $\mathrm{DI}$, Takahara $\mathrm{H}$, et al. Human vascular smooth muscle cells of diabetic origin exhibit increased proliferation, adhesion, and migration. J Vasc Surg. 2001; 33(3): 601-7

19. Devine SM, Liedtke AJ, Zelis R. Coronary artery disease in diabetic patients. In: Scott R, (ed.) Clinical cardiology and diabetes, vol. II. Mt Kisco, NY: Futura Publishing Co; 1981. p. 1-87.

20. Campisi R, Di Carli MF. Assessment of coronary flow reserve and microcirculation: a clinical perspective. J Nucl Cardiol. 2004; 11: 3-11.

21. Langer A, Freeman MR, Josse RG, et al. Metaiodobenzylguanidine imaging in diabetes mellitus: assessment of cardiac sympathetic denervation and its relation to autonomic dysfunction and silent myocardial ischemia. J Am Coll Cardiol. 1995; 25: 6108.

22. Di Carli MF, Bianco-Batlles D, Landa ME, et al. Effects of autonomic neuropathy on coronary blood flow in patients with diabetes mellitus. Circulation. 1999; 100: 813-9.

23. Nesto RW, Watson FS, Kowalchuk GJ, et al. Silent myocardial ischemia and infarction in diabetics with peripheral vascular disease: assessment by dipyridamole thallium-201 scintigraphy. Am Heart J 1990; 120: 1073-7.

24. Koistinen MJ. Prevalence of asymptomatic myocardial ischemia in diabetic subjects. BMJ. 1990; 301: 92-5.

25. Milan Study on Atherosclerosis and Diabetes Group. Prevalence of unrecognized silent myocardial ischemia and its association with atherosclerotic risk factors in noninsulin-dependent diabetes mellitus. Am J Cardiol. 1997; 79: 134-9.

26. Janand-Delenne B, Savin B, Habib G, et al. Silent myocardial ischemia in patients with diabetes: who to screen. Diabetes Care. 1999; 22: 1396-400.

27. Goraya TY, Leibson CL, Palumbo PJ, et al. Coronary atherosclerosis in diabetes mellitus: a populationbased autopsy study. J Am Coll Cardiol 2002; 40: 946 53.

28. Rivera JJ, Nasir K, Choi EK, et al. Detection of occult coronary artery disease in asymptomatic individuals with diabetes mellitus using non-invasive cardiac angiography. Atherosclerosis. 2009; 203(2): 442-8.

29. Mark DB, Lee KL, Bengtson JR, et al. Prognostic value of a treadmill Exercise score in Outpaqtients with Suspected Coronary Artery Disease. N Eng J Med. 1991; 325: 849-53.

30. Vacanti LJ, Sespedes LBH, Santos MOS. Exercise stress testing is useful, safe, and efficient even in patients aged 75 years or older. Arq Bras Cardiol. 2004; 82(2): 151-4.

31. Goldhammer S, Scherf D. Elektrokardiographische untersuchungen bei kranken mit angina perctoris ("ambulatorischer Typus"). Z Klin Med. 1932; 122: 134.

32. $\mathrm{Li} \mathrm{D,} \mathrm{Li} \mathrm{CY,} \mathrm{Yong} \mathrm{AC,} \mathrm{et} \mathrm{al.} \mathrm{Source} \mathrm{of}$ electrocardiographic ST changes in subendocardial ischemia. Circ Res. 1998; 82(9): 957-70.

33. Bacci $S$, Villella $M$, Villella $A$, et al. Screening for silent myocardial ischaemia in type 2 diabetic patients with additional atherogenic risk factors: applicability and accuracy of the exercise stress test. Euro J Endocrinol. 2002; 147: 649-54.

34. Bossone E, Armstrong WF. Exercise echocardiography: principles, methods \& clinical use. Cardiol Clin. 1999; 17: 447-60.

35. Yao SS, Rozanski A. Principal uses of myocardial perfusion scintigraphy in the management of patients with known or suspected coronary artery disease. Prog Cardiovasc Dis. 2001; 43: 281-302.

36. Rajagopalan N, Miller TD, Hodge DO, Frye RL, Gibbons RJ. Identifying high-risk asymptomatic diabetic patients who are candidates for screening stress single-photon emission computed tomography imaging. J Am Coll Cardiol. 2005; 45: 43-9.

37. Bellasi A, Paolo Raggi, Bairey Merz CN, Shaw LJ. New insights into ischemic heart disease in women. Cleveland Clin J Med. 2007; 74: 585-94.

38. May $O$, Arildsen $H$, Damsgaard EM, et al. Prevalence and prediction of silent ischaemia in diabetes mellitus: a population-based study. Cardiovasc Res. 1997; 34(1): 241-7.

39. Al-Oqaily QA, Assessment of Complete Blood Countin Patients with Coronary Artery Disease. Iraqi Journal of Medical Sciences 2014; 12 (1): 82.

40. Al-Mukhtar SB, Fadhil NN, Hanna BE. General and gender characteristics of type 2 diabetes mellitus among the younger and older age groups. Oman Med J. $2012 ; 27(5)$ : 375-82.

41. Wagner JD. Effects of sex steroid treatment on the cardiovascular system. Infertil Reprod Med Clinics of North America. 2001; 12: 511-33.

42. Hodis HN, Mack WJ, Lobo RA, et al. Estrogen in the prevention of atherosclerosis. A randomized, doubleblind, placebo-controlled trial. Ann Intern Med. 2001; 135(11): 939-53.

\section{Correspondence to Dr. Nabeel N.F. Hadeed E-mail: nabeelnfadhil@yahoo.com Received $10^{\text {th }}$ Feb. 2016: Accepted $9^{\text {th }}$ June 2016}

